\title{
APLIKASI PEMESANAN RUANG RAPAT BERBASIS JAVA PADA PT. AMITHYA SATYA LARAS
}

\author{
Muhamad Saddam Aldinov ${ }^{1}$, Maria Cleopatra ${ }^{2}$, Noor Komari Pratiwi ${ }^{3}$ \\ 1,2,3 Universitas Indraprasta PGRI \\ Jl. Raya Tengah No. 80, Kel Gedong, Kec. Pasar Rebo, Jakarta Timur 13760, Jakarta \\ saddamaldnv@gmail.com, mariacleopatra1313@gmail.com, noorkomaripratiwi01@gmail.com
}

\begin{abstract}
ABSTRAK
PT. Amithya Satya Laras merupakan sebuah perusahaan dalam bidang jasa sewa ruang rapat yang berlokasi di Pasar Minggu, Jakarta Selatan. Proses pemesanan ruangan dan laporan dari setiap transaksi masih menggunakan sistem manual dengan bantuan Microsoft office. Hal ini menyebabkan proses transaksi dan laporan kurang efektif dan efisien. Tujuan dari penelitian ini untuk memudahkan bagian pemasaran dalam melakukan transaksi pemesanan ruang rapat serta mempermudah proses laporan pembayaran dan sewa ruangan. Metode penelitian yang digunakan adalah penelitian kualitatif dengan studi lapangan. Metode pengambilan data yaitu melalui pengamatan langsung, wawancara dengan pihak terkait, dan melakukan dokumentasi untuk mendapatkan informasi yang dibutuhkan. Sistem dikembangkan dengan menggunakan metode waterfall. Perancangan yang digunakan untuk sistem ini dengan tools yaitu Unified Modelling Language (UML). Dapat disimpulkan, sistem ini dapat mempermudah pekerjaan bagian pemasaran dalam melakukan proses transaksi pemesanan serta laporan pada PT. Amithya Satya Laras.
\end{abstract}

Kata Kunci: Sistem, Aplikasi, Pemesanan, Ruang Rapat

\begin{abstract}
PT. Amithya Satya Laras is a company engaged in meeting room rental services located in Pasar Minggu, South Jakarta. The room reservation process and reports from each transaction still use a manual system with the help of Microsoft Office. This causes the transaction process and reports to be less effective and efficient. The purpose of this study is to facilitate the marketing department in making meeting room reservations and simplify the process of payment reports and room rentals. The research method used is qualitative research with field studies. The data collection method is through direct observation, interviews with related parties, and conducting documentation to obtain the required information. The system was developed using the waterfall method. The design used for this system with tools, namely Unified Modeling Language (UML). It can be concluded, this system can facilitate the work of the marketing department in processing ordering transactions and reports to PT. Amithya Satya Laras.
\end{abstract}

Key Word: System, Application, Reservation, Meeting Rooms.

\section{PENDAHULUAN}

Perkembangan teknologi informasi yang terjadi di era saat ini mempermudah pengguna untuk menggunakan teknologi informasi dalam menyelesaikan pekerjaannya. Banyak organisasi dan instansi, baik pemerintah maupun badan usaha, memanfaatkan perkembangan teknologi informasi. Penggunaan komputer dalam penanganan dan pengolahan data memerlukan suatu prosedur yang tepat, dalam hal ini adalah perangkat lunak aplikasi atau disebut juga program. Pengolahan data yang tepat dan cepat mampu meningkatkan kinerja (Yusuf et al., 2021).

Aplikasi berbasis desktop memberikan manfaat dan lebih memudahkan bagi setiap pengguna komputer atau laptop dalam pengelolaan data sehingga dapat memberikan hasil laporan yang lebih akurat. Meskipun saat ini banyak pengguna yang beralih ke smartphone Android dan iOS, namun aplikasi desktop masih sangat efektif digunakan. Hal tersebut disebabkan oleh terbatasnya perangkat Android dan iOS untuk mencetak laporan (Kurniawan \& Syahputra, 2018).

Setiap perusahaan, baik swasta maupun instansi pemerintah, tidak akan pernah bisa terlepas dari suatu kegiatan yang disebut dengan meeting atau rapat. Kegiatan ini dilakukan untuk membicarakan hal-hal penting dalam pengambilan keputusan (Maulana et al., 2021).

PT. Amithya Satya Laras merupakan sebuah perusahaan dalam bidang jasa, yakni jasa penyewaan ruang rapat. Layanan yang 
disediakan berupa penyewaan ruang rapat yang berlokasi di Jakarta. PT. Amithya Satya Laras juga menjamin tersedianya fasilitas yang optimal untuk para client-nya. Dengan fasilitas ruang rapat yang nyaman, serta pelayanan yang profesional, diharapkan dapat meningkatkan produktivitas usaha.

Dalam kegiatan bisnisnya, PT. Amithya Satya Laras belum mempunyai sebuah aplikasi yang dapat mendukung sistem pemesanan ruang rapat. Dalam proses pemesanan ruang rapat, bagian pemasaran masih menggunakan sistem manual. Staf harus menyimpan semua data secara manual dengan bantuan Microsoft office di setiap kegiatannya. Oleh karena itu, banyak laporan tumpang tindih dan proses transaksi tidak terintegrasi dengan sistem pemesanan. Pengelolaan data yang belum optimal tersebut perlu dibenahi dengan sistem baru yang terkomputerisasi dan terintegrasi dengan baik agar pengolahan data menjadi efektif serta efisien.

Tujuan dari penelitian ini adalah untuk memudahkan bagian pemasaran dalam melakukan transaksi pemesanan serta mempermudah proses laporan pembayaran dan sewa ruangan.

Menurut teori, pemesanan adalah proses, perbuatan, cara memesan atau memesankan (Hizair, 2012). Kemudian, rapat merupakan bentuk komunikasi yang dihadiri oleh banyak orang dengan tujuan membahas suatu permasalahan tertentu. Melalui rapat, suatu masalah dapat dipecahkan, kebijakan organisasi dirumuskan, serta perkembangan organisasi dilahirkan (Dewi, 2011).

Perancangan adalah sebuah proses pengembangan spesifikasi baru yang berdasarkan rekomendasi hasil analisis sistem (Subhan, 2012). Sedangkan, sistem adalah sekelompok unsur yang erat hubungannya satu dengan yang lain, berfungsi bersamasama untuk mencapai tujuan tertentu (Sutabri, 2012).

Aplikasi merupakan penerapan, menyimpan sesuatu hal, data, permasalahan, pekerjaan kedalam suatu sarana atau media yang dapat digunakan untuk diterapkan menjadi sebuah bentuk yang baru (Hartono, 2014).
Berdasarkan penjelasan di atas, dirancanglah aplikasi desktop pemesanan ruang rapat berbasis java pada PT. Amithya Satya Laras. Dengan menggunakan sistem aplikasi ini, proses transaksi pemesanan dan pembuatan laporan akan menjadi efektif dan juga efisien.

\section{METODE PENELITIAN}

Penulis menggunakan metode penelitian kualitatif, yaitu metode pengumpulan data pada suatu latar alamiah dengan maksud menafsirkan fenomena yang terjadi dimana peneliti adalah sebagai instrumen kunci (Anggito \& Setiawan, 2018).

Langkah-langkah pengembangan sistem yang diterapkan pada penelitian ini menggunakan metode waterfall. Metode waterfall adalah metode pengembangan sistem informasi yang sistematis dan berurutan. Metode waterfall memiliki lima fase: analisis dan definisi kebutuhan, desain sistem dan perangkat lunak, implementasi dan pengujian unit, integrasi dan pengujian sistem, serta operasi dan pemeliharaan (Sommerville, 2011).

Rancangan kegiatan penelitian dimulai pada bulan April 2021 dengan kunjungan langsung ke lapangan untuk mencatat hal-hal penting mengenai suatu masalah, lalu melakukan wawancara langsung dengan pihak yang bersangkutan yaitu staf pemasaran pada PT. Amithya Satya Laras.

Dalam membangun sistem aplikasi ini, menggunakan tools yang berupa Unified Modelling Language atau biasa disingkat UML, yaitu bahasa visual yang digunakan untuk pemodelan dan komunikasi mengenai sebuah sistem dengan menggunakan diagram dan teks pendukung (Rosa \& Shalahuddin, 2015). Sedangkan bahasa pemrograman yang digunakan adalah java dan database yang digunakan adalah MySQL.

Dari sekian banyaknya bahasa pemograman yang dapat dijalankan di berbagai sistem operasi, salah satunya adalah bahasa pemrograman java (Nofriadi, 2015).

MySQL merupakan software yang ada dalam sistem manajemen basis data SQL (Database Management System) yang juga dikenal dengan DBMS multithread dan multi-user (Yudhanto \& Purbayu, 2014). 


\section{HASIL DAN PEMBAHASAN}

Setelah melakukan pengamatan, peneliti mengidentifikasi permasalahan yang ada di tempat penelitian adalah sebagai berikut.

1. Form lembar pemesanan dan buku pemesanan sering terjadi redudansi dan kesalahan dalam entri data.

2. Sulitnya pencarian data pemesanan karena data masih belum tersimpan dengan rapi sehingga memerlukan waktu yang lama.

3. Perhitungan transaksi pembayaran untuk pemesanan fasilitas yang tersedia sewaktuwaktu dapat terjadi kesalahan. Hal ini membuat bagian pemasaran harus melakukan pengecekan berulang kali.

Dari beberapa masalah yang ada di atas, dibutuhkan alternatif pemecahan masalah sebagai berikut.

1. Membangun sebuah aplikasi untuk menyimpan data dengan database sehingga tidak terjadi redudansi dan kesalahan dalam entri data.

2. Membangun sebuah aplikasi agar dapat memudahkan pencarian data pemesanan.

3. Membangun sebuah aplikasi untuk mengolah perhitungan transaksi pembayaran fasilitas yang dipesan.

\section{Use Case Diagram}

Berikut Use Case Diagram diusulkan yaitu:

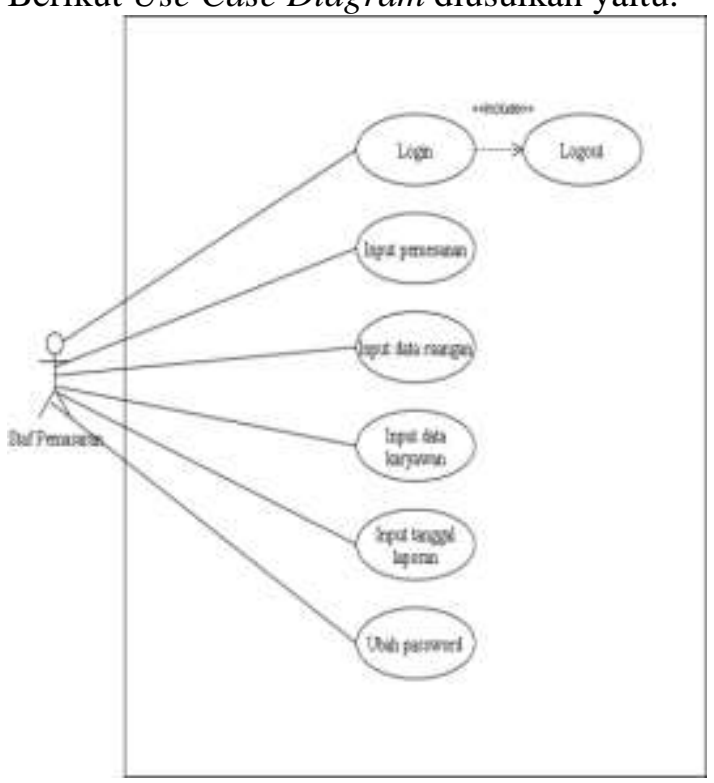

Gambar 1. Use Case Diagram

\section{Class Diagram}

Berikut Class Diagram yang diusulkan yaitu:

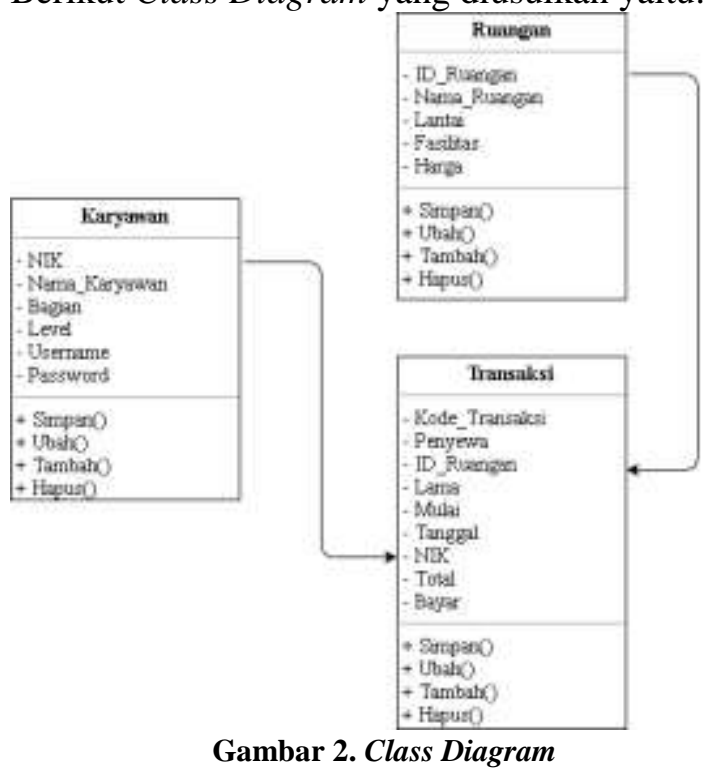

\section{Entity Relationship Diagram (ERD)}

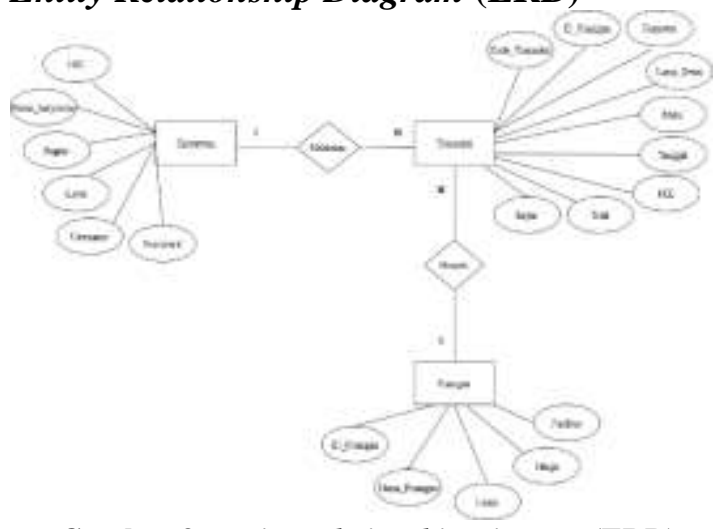

Gambar 3. Entity Relationship Diagram (ERD)

\section{Tampilan Halaman Login}

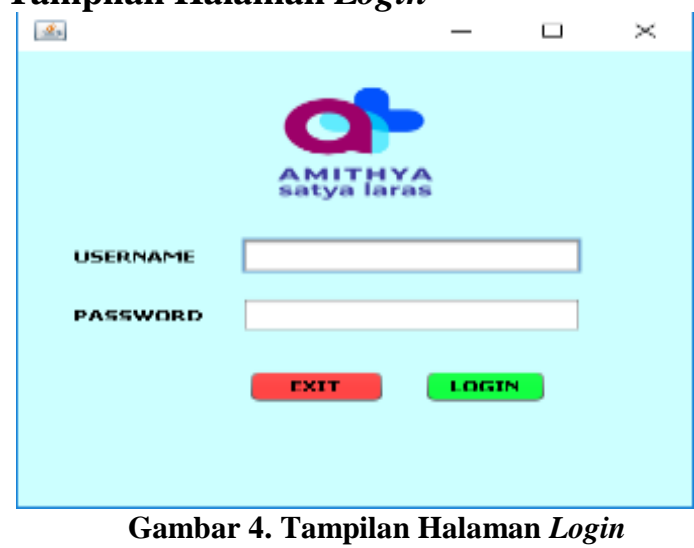

Pada tampilan awal menjalankan aplikasi ini menampilkan form login. Pengguna diharuskan memasukkan username beserta password untuk bisa login ke halaman menu utama. 


\section{Tampilan Menu Utama}

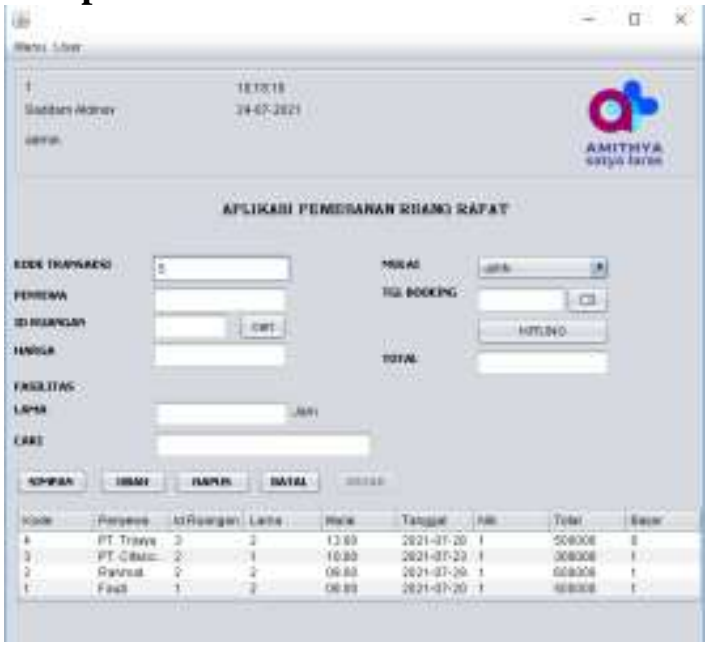

Gambar 5. Tampilan Menu Utama

Pada tampilan ini menampilkan menu utama sekaligus form pemesanan ruang rapat yang dapat diisi oleh bagian pemasaran dalam melakukan transaksi.

\section{Tampilan Laporan Data Ruangan}

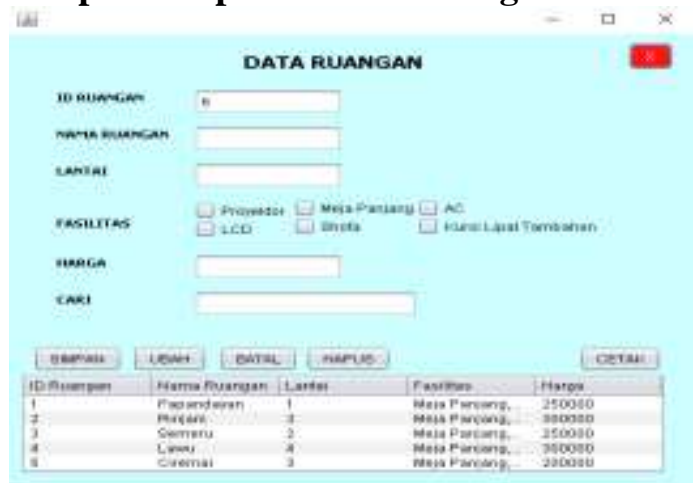

Gambar 6. Tampilan Laporan Data Ruangan

Pada tampilan ini menampilkan data ruangan yang dapat ditambahkan dan diubah serta dapat dicetak.

\section{Tampilan Laporan Data Karyawan}

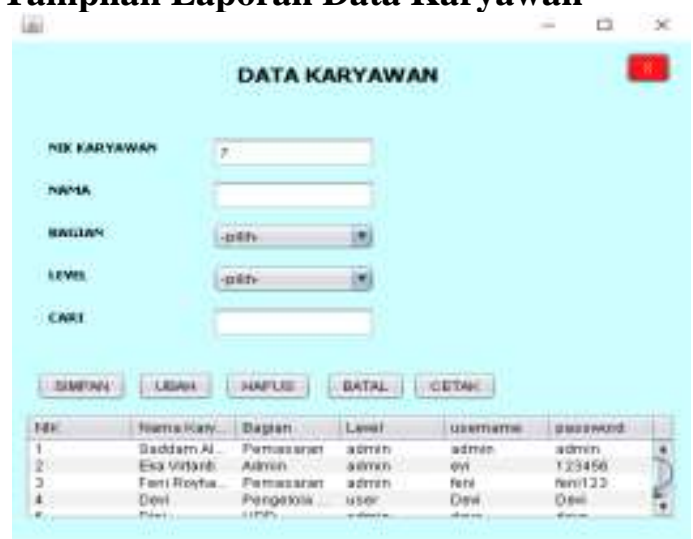

Gambar 7. Tampilan Laporan Data Karyawan
Pada bagian ini menampilkan daftar karyawan yang dapat ditambahkan dan diubah serta dapat dicetak.

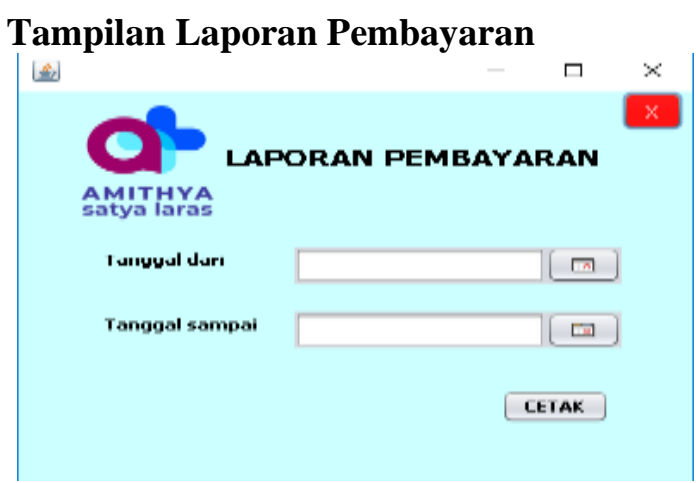

Gambar 8. Tampilan Laporan Pembayaran

Pada tampilan ini menampilkan sebuah kolom untuk memasukkan tanggal, agar dapat mencetak laporan pembayaran sesuai dengan tanggal/periode yang diperlukan.

\section{Tampilan Laporan Sewa Ruang}

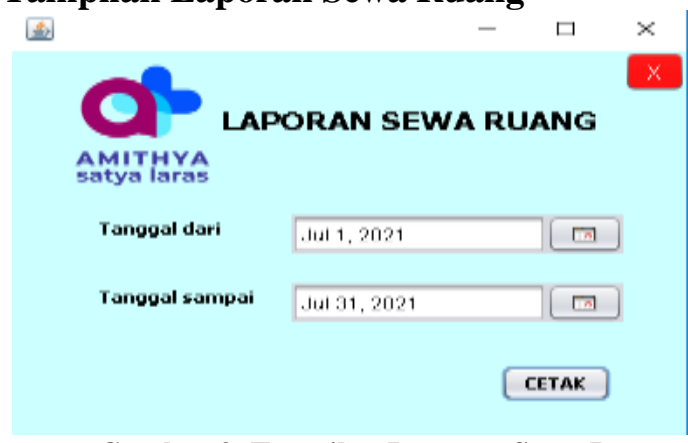

Gambar 9. Tampilan Laporan Sewa Ruang

Pada tampilan ini menampilkan sebuah kolom untuk memasukkan tanggal, agar dapat mencetak laporan sewa ruang sesuai dengan tanggal/periode yang diperlukan.

\section{Tampilan Ubah Password}

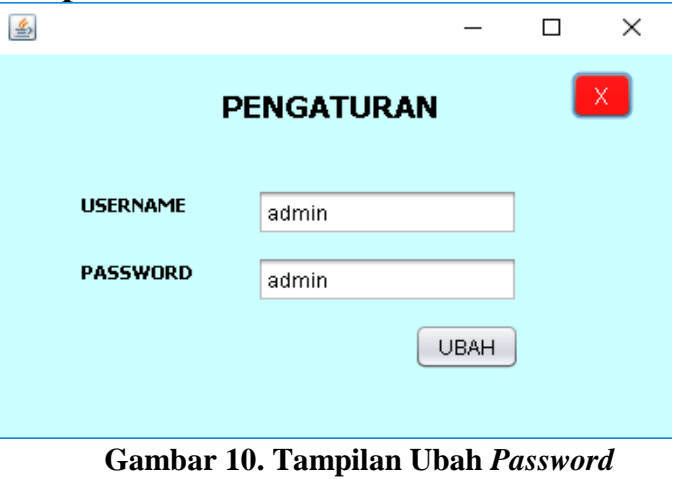

Pada tampilan ini menampilkan sebuah kolom username beserta password yang ingin diubah. 


\section{Tampilan Cetak Bukti Pembayaran}

\begin{tabular}{l} 
BUKTI PEMBAYARAN \\
PT. AMITHYA SATYA LARAS \\
\hline Kodn Transaksi : 1 \\
Penyewa $\quad$ :Fauzi \\
$\begin{array}{ll}\text { Nama Ruangan } & : \text { Papandayan } \\
\text { Tanggal } & : 20 \text { Jull } 2021 \\
\text { Jam Mulai } & : 08.00 \\
\text { Durasi } & : 2 \text { Jam } \\
\text { Total } & : \text { Rp } 500.000\end{array}$
\end{tabular}

Jakarta, 26 Juli 2021

Saddam Aldinov

Gambar 11. Tampilan Cetak Bukti Pembayaran

Pada tampilan ini menampilkan sebuah bukti pembayaran transaksi yang telah dicetak, yang dapat dijadikan bukti transaksi.

\section{Tampilan Cetak Laporan Data Ruangan}

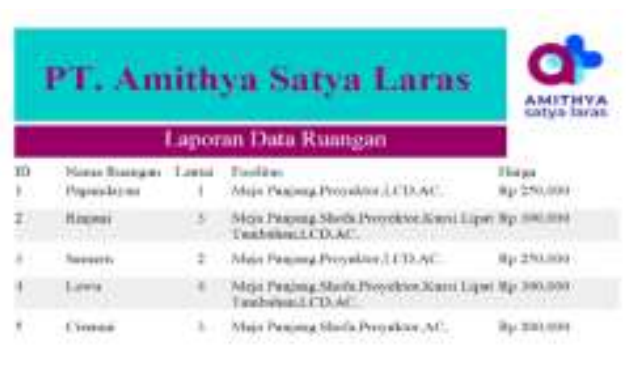

Tata somber:

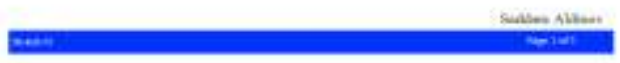

Gambar 12. Tampilan Cetak Laporan Data Ruangan

Pada tampilan ini menampilkan sebuah laporan data ruangan yang telah dicetak.

Tampilan Cetak Laporan Data Karyawan

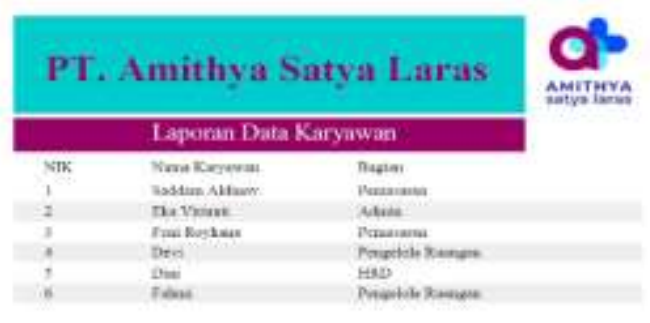

tan. at atanget

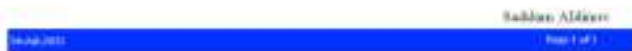

Gambar 13. Tampilan Cetak Laporan Data Karyawan

Pada tampilan ini menampilkan sebuah laporan data karyawan yang telah dicetak. 


\section{Tampilan Cetak Laporan Data Pembayaran}

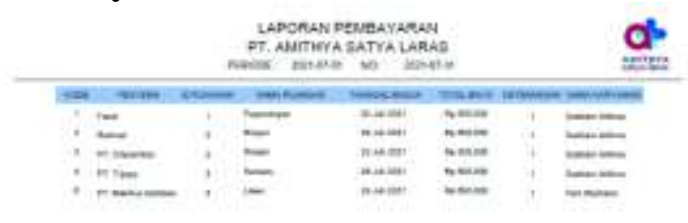

\section{(20) \\ Gambar 14. Tampilan Cetak Laporan Data Pembayaran}

Pada tampilan ini menampilkan sebuah laporan pembayaran yang telah dicetak.

\section{Tampilan Cetak Laporan Sewa Ruang}

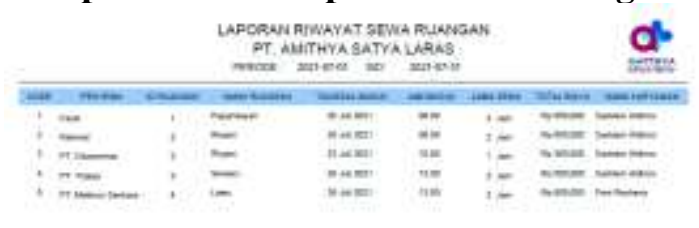

Gambar 15. Tampilan Cetak Laporan Pembayaran

Pada tampilan ini menampilkan sebuah laporan sewa ruangan yang telah dicetak.

\section{SIMPULAN DAN SARAN}

Peniliti memiliki simpulan sebagai berikut: Dengan sistem ini memudahkan bagian pemasaran dalam membuat suatu transaksi pemesanan ruang rapat serta membuat suatu laporan.

Dengan sistem yang terkomputerisasi ini, kesalahan dapat terdekteksi dan dengan cepat dapat diperbaiki. Sistem ini dapat meningkatkan efektifitas dan efisiensi kerja karyawan di PT. Amithya Satya Laras.

Sejalan dengan sistem yang penulis buat, penulis mengemukakan saran bahwa sistem aplikasi ini masih harus ditingkatkan lagi, baik dari segi fitur maupun pemeliharaannya, agar dapat memenuhi kebutuhan perusahaan ke depannya serta tidak menghambat operasional perusahaan.

Aplikasi pendukung ini bisa dioptimalkan dengan melakukan pengembangan fitur-fitur yang dibutuhkan agar dapat mempermudah pengguna, seperti terintegrasi dengan sistem departemen lain. Aplikasi pendukung ini bisa dikembangkan lagi dalam tampilan interfacenya supaya pengguna merasa lebih nyaman, mudah, dan cepat dalam menggunakannya.

Petugas-petugas yang telah ditunjuk perlu melakukan pengawasan secara berkala dalam proses pemeliharaan sistem komputer.

Backup data harus selalu dilakukan dalam suatu periode tertentu agar terhindar dari halhal yang tidak diinginkan yang bersifat merugikan.

Hasil penelitian ini sama dengan hasil penelitian yang menyimpulkan bahwa perancangan aplikasi Booking Meeting Room pada PT. Kimia Farma dapat menjadi solusi untuk pemesanan ruang rapat yang lebih efektif dan efisien (Prayitno et al., 2020).

\section{UCAPAN TERIMAKASIH}

Peneliti mengucapkan terima kasih untuk keluarga besar PT. Amithya Satya Laras yang telah memberikan kesempatan kepada peniliti sehingga peneliti dapat menyelesaikan penelitian ini dengan baik.

\section{DAFTAR PUSTAKA}

Anggito, A., \& Setiawan, J. (2018). Metodologi Penelitian Kualitatif. Cv Jejak.

Dewi, I. C. (2011). Manajemen Kesekretariatan: Untuk Smk, Perguruan Tinggi Dan Praktisi. Prestasi Pustaka.

Hartono, J. (2014). Analisis Dan Desain Sistem Informasi. Andi Offset.

Hizair, M. (2012). Kamus Lengkap Bahasa Indonesia. Tamer.

Ismunandar, A. R. N., Afrizal, T., \& Dwitiyanti, N. (2021). Aplikasi Penjualan Aksesoris Handphone Pada Asia Accessories Hp. Seminar Nasional Riset Dan Inovasi Teknologi (Semnas Ristek), 86-91.

Kurniawan, E., \& Syahputra, A. K. (2018). Perancangan Aplikasi Pemesanan Dan Pembayaran Berbasis Desktop Pada Percetakan Ud. Azka Gemilang Menggunakan Metode Prototype. Seminar Nasional Raya, 9986(September), 105-110.

Maulana, A., Septianzah, K., \& Hartuti, P. M. (2021). Sistem Pemesanan Meeting Room 
Di Pt. Saptaindra Sejati Menggunakan Teknologi Java Netbeans. Seminar Nasional Riset Dan Inovasi Teknologi (Semnas Ristek), 73-78.

Nofriadi. (2015). Java Fundamental Dengan Netbeans 8.0.2. Deepublish.

Prayitno, E., Maisyaroh, M., Santoso, B., \& Apriantini, T. (2020). Rancang Bangun Sistem Informasi Booking Meeting Room Online Pada Pt. Kimia Farma. Smart Comp :Jurnalnya Orang Pintar Komputer, 9(2),

89-91.

Https://Doi.Org/10.30591/Smartcomp.V9i2. 1902

Rosa, A. S., \& Shalahuddin, M. (2015). Rekayasa Perangkat Lunak. Penerbit Informatika.

Sommerville, I. (2011). Software Engineering (Rekayasa Perangkat Lunak). Erlangga.

Subhan, M. (2012). Analisa Perancangan Sistem. Lentera Ilmu Cendekia.

Sutabri, T. (2012). Konsep Sistem Informasi. Andi Offset.

Yudhanto, Y., \& Purbayu, A. (2014). Toko Online Dengan Php Dan My Sql. Elex Media Komputindo.

Yusuf, D., Afrizal, T., \& Budiarto, A. (2021). Perancangan Sistem Aplikasi Pemesanan Lapangan Futsal Berbasis Java Pada Wirabujana Futsal Indramayu. Journal of Information System, Applied, Management, Accounting And Research (Jisamar), 5(1), 125-131.

Http://Journal.Stmikjayakarta.Ac.Id/Index.P hp/Jisamar/Article/View/347 